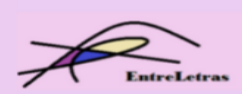

REVISTA ENTRELETRAS (ARAGUAÍNA), V. 12, N. 3, SET./DEZ. 2021 (ISSN 2179-3948 - ONLINE)

\title{
XICOTÉNCATL (1826) NO POLISSISTEMA LATINO-AMERICANO E A SUA TRADUÇÃO: \\ UMA REFLEXÃO POSSÍVEL DO ENTRE-LUGAR E A DESCONSTRUÇÃO DE HERNÁN CORTÉS
}

\author{
XICOTÉNCATL (1826) EN EL POLISISTEMA LATINOAMERICANO Y SU \\ TRADUCCIÓN: \\ UNA REFLEXIÓN POSIBLE A PARTIR DEL ENTRELUGAR Y LA \\ DECONSTRUCCIÓN DE HERNÁN CORTÉS
}

DOI 10.20873/uft2179-3948.2021v12n3p46-67

\author{
Jorge Antonio Berndt ${ }^{1}$ \\ Leila Shaí Del Pozo González ${ }^{2}$ \\ Phelipe de Lima Cerdeira ${ }^{3}$
}

\begin{abstract}
Resumo: Este artigo toma a tradução ao português brasileiro de Xicoténcatl (1826) para exemplificar a teoria dos polissistemas (EVEN-ZOHAR, 1978) nos estudos da tradução. Sublinha-se como a ressignificação da personagem Hernán Cortés na diegese permite a (des)construção de certos saberes (SOUSA SANTOS, 2010; QUIJANO, 2014), tensionando um dado constructo imposto pela linhagem historiográfica rankeana e motivando os intelectuais no entre-lugar do discurso latino-americano (SANTIAGO, 2000). Estão circunscritas à nossa análise as recentes discussões sobre as fases e modalidades do romance histórico (FLECK, 2017), ademais de elaborações para pensar na ficção histórica no contexto latino-americano (WEINHARDT, 2011), (CERDEIRA, 2019), entre outros.
\end{abstract}

\footnotetext{
${ }^{1}$ Mestrando do Programa de Pós-graduação em Letras, com Área de Concentração em Linguagem e Sociedade, da Universidade Estadual do Oeste do Paraná-Unioeste. Bolsista da Fundação Araucária. Participante do programa de extensão universitária PELCA - Programa de Ensino de Literatura e Cultura, da mesma casa de estudos. Participante do projeto de pesquisa "Ressignificações do passado na América: leitura, escrita e tradução de gêneros híbridos de história e ficção - vias para a descolonização", nas linhas de pesquisa b- Releituras da história pela ficção: estudos comparados; c- A tradução no espaço latino-americano: práticas tradutórias e sua importância, vinculado ao PELCA. ORICD: https://orcid.org/0000-0002-6691-1777. E-mail: jorgeberndt@ outlook.com.ar

2 Doutoranda do Programa de Pós-graduação em Letras, com Área de Concentração em Linguagem e Sociedade, da Universidade Estadual do Oeste do Paraná-Unioeste. Bolsista CAPES. Participante do projeto de pesquisa "Ressignificações do passado na América: leitura, escrita e tradução de gêneros híbridos de história e ficção - vias para a descolonização", nas linhas de pesquisa b- Releituras da história pela ficção: estudos comparados; c- A tradução no espaço latino-americano: práticas tradutórias e sua importância, vinculado ao PELCA. Researcher ID: F-1106-2018. http://orcid.org/0000-0002-2654-0414. Participante do programa de extensão universitária PELCA - Programa de Ensino de Literatura e Cultura, da mesma casa de estudos. E-mail: leilashai@ @otmail.com

${ }^{3}$ Doutor em Letras - Estudos Literários (UFPR/Temporada sanduíche UNC-Argentina). Professor Adjunto de Língua Espanhola e suas literaturas na Universidade do Estado do Rio de Janeiro (UERJ), Instituto de Letras. Pósdoutorado em Literatura Comparada na Universidade Estadual do Oeste do Paraná (UNIOESTE). Participante do projeto de pesquisa "Ressignificações do passado na América: leitura, escrita e tradução de gêneros híbridos de história e ficção - vias para a descolonização", nas linhas de pesquisa b- Releituras da história pela ficção: estudos comparados; c- A tradução no espaço latino-americano: práticas tradutórias e sua importância, vinculado ao PELCA. ORCID: https://orcid.org/0000-0002-9097-8250. E-mail: phelipecerdeira@gmail.com
} 


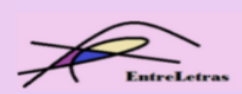

REVISTA ENTRELETRAS (ARAGUAÍNA), V. 12, N. 3, SET./DEZ. 2021 (ISSN 2179-3948 - ONLINE)

Palavras-chave: Xicoténcatl (1826), primeiro romance histórico latino-americano; literatura hispano-americana; estudos da tradução; polissistemas; tradução literária.

Resumen: Este artículo elige la traducción al portugués brasileño de Xicoténcatl (1826) para poner ejemplo en la teoría de los polisistemas (EVEN-ZOHAR, 1978). Se subraya que la resignificación del personaje Hernán Cortés en la diégesis garantiza la (de)construcción de saberes (SOUSA SANTOS, 2010; QUIJANO, 2014), tensionando lo establecido por el linaje historiográfico rankeano y estimulando a los intelectuales en el entrelugar del discurso latinoamericano (SANTIAGO, 2000). Forman parte de este marco teórico las discusiones acerca de las fases y modalidades de la novela histórica (FLECK, 2017), tal cual los postulados sobre la ficción histórica (WEINHARDT, 2011), (CERDEIRA, 2019), y otros más.

Palabras claves: Xicoténcatl (1826), primera novela histórica latinoamericana; literatura hispanoamericana; estudios de la traducción; polisistemas; traducción literaria.

\section{Introdução: de um império asteca invadido a um continente (re)conquistado}

O mundo já tinha presenciado incursões de bárbaros semisselvagens que, abandonando seus covis e seu ingrato país, apossaram-se de regiões de climas mais benéficos, destruindo aqueles que aí habitavam desde a antiguidade; alguns desses vândalos, inclinados pela ambição, instalados em posições de liderança desses povos ancestrais, armaram-se para enfrentar nações irmãs umas contra as outras, com o objetivo de subjugar a todas. (ANÔNIMO, 2020, p. 99).

O excerto escolhido como introito desta leitura obedece a questões que transcendem à paratextualidade já arrolada por Genette em Palimpsestos: a literatura de segunda mão (2010). Ainda que entendamos que tal escolha não seja aleatória, já que dialoga diretamente com a proposta adotada na fase acrítica e pela modalidade clássica scottiana (FLECK, 2017 $)$ de levar às diegeses híbridas uma constelação de obras que se retroalimentam, construindo laberintos de infinitas possibilidades ou uma sorte de Biblioteca de Babel pensada por Borges em suas Ficções ([1944], 1974), em que história e ficção protagonizam os seus encontros e desencontros

\footnotetext{
${ }^{4}$ Ao evidenciar a sequência da trajetória do romance histórico, de acordo com o que Fleck (2017) propõe, existem dois grupos: de obras acríticas e críticas. De modo global elas projetam três fases: acrítica; crítica/desconstrucionista; crítica/mediadora; e cinco modalidades: 1- o romance histórico clássico scottiano; 2- o romance histórico tradicional (ambos integram o primeiro grupo de romances e, também, da primeira fase do gênero); 3- O novo romance histórico latino-americano; 4- A metaficção historiográfica (Ambas pertencentes ao segundo grupos de romances e, também, integrantes da segunda fase da trajetória do gênero); 5 - O romance histórico contemporâneo de mediação (conjunto de obras que integra o segundo grupo e compõem a terceira fase da trajetória do gênero). Para mais informações, sugerimos a leitura de Fleck (2017), nas referências.
} 


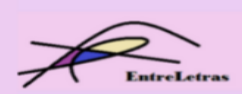

REVISTA ENTRELETRAS (ARAGUAÍNA), V. 12, N. 3, SET./DEZ. 2021 (ISSN 2179-3948 - ONLINE)

(CERDEIRA, 2019), o desafio, aqui, não era exatamente este. Trata-se, pois, de uma primeira provocação com os nossos interlocutores, um posicionamento epistemológico para responder àqueles postulados do porta-voz de Nuestra América (MARTÍ, [1889], 1891), uma oportunidade de retomar os anseios de críticos como o venezuelano Arturo Uslar Pietri (1990), ao relembrar a necessidade de que, enquanto latino-americanos, tenhamos consciência de não seguir os ventos, tais como caravelas, de fantasmas-questões de um mundo morto, alheio à(s) nossa(s) realidades de cá.

A escolha pelo fragmento que aponta, já logo no primeiro parágrafo do Livro I de Xicoténcatl (1826), a voz crítica de um narrador heterodiegético também nos permite vislumbrar ao menos outros três argumentos iniciais: i) o de levar aos receptores a expansão da fortuna crítica da recente tradução ao português brasileiro do primeiro romance histórico latinoamericano ${ }^{5}$; ii) o de precisar como tal ação tradutória acaba (nos) permitindo reconhecer certas obras que fissuraram a acriticidade esperada - e majoritária - para um dado momento de produção ficcional de romance histórico em contextos de projetos de formação de nações (SOMMER, 2004) e de grande emulação de padrões românticos forâneos; iii) e, fundamentalmente para o exercício nodal deste artigo, (des)articular a cristalização de certo imaginário positivista que entendia a tradução como simples prática de consolidação de um dado campo de poder, pensando em termos bourdianos, relegando, durante muitos anos, à tradução o seu potencial artístico expressivo de reflexão e, ainda, enquanto exercício discursivo de negociação, de reconhecimento e de potencial de expressão de um dito entre-lugar (SANTIAGO, 2000).

Vale lembrar que, em seu breve estudo crítico de apresentação de Xicoténcatl, o próprio tradutor e pesquisador, já capitalizava a respeito de como o

[...] discurso crítico de Xicoténcatl frente às atrocidades da conquista do México, liderada pelas ações e comando de Hernán Cortés, ressoa sem ecos nas demais colônias americanas, já independentes à época, ou ainda em luta pela reconquista de seu território, como era o caso do México. As colônias, ou ex-colônias seguiam, pois, atreladas aos ditames europeus, dependentes da "voz autorizada" para julgar a "qualidade" da arte literária [...] (FLECK, 2020, p. 44).

\footnotetext{
${ }^{5}$ A tradução do primeiro romance histórico latino-americano e mexicano, Xicoténcatl (1826), deu-se após 194 anos da sua publicação. A publicação da versão em português brasileiro de Fleck (2020) conta com um estudo introdutório crítico da obra, com base em leituras preliminares das diferentes edições, leitura da tradução ao inglês, pesquisas para Trabalho de Conclusão de Curso, escrita de artigos, pesquisa para Dissertação de Mestrado em Letras, como parte dos estudos do grupo de pesquisa "Ressignificações do passado na América: processos de leitura, escrita e tradução de gêneros híbridos de história e ficção - vias para a descolonização". Mais informações podem ser consultadas na seção de Referências.
} 


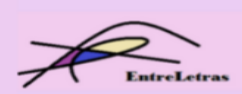

REVISTA ENTRELETRAS (ARAGUAÍNA), V. 12, N. 3, SET./DEZ. 2021 (ISSN 2179-3948 - ONLINE)

Sendo assim, entendendo o nosso lócus de enunciação enquanto pesquisadores e tradutores latino-americanos e, ao mesmo tempo, tomando a já referida tradução de Xicoténcatl (1826) - o primeiro romance histórico latino-americano - como um ponto de inflexão para os estudos da tradução das literaturas hispânicas para o português brasileiro, promovemos o ponto de partida desta leitura. Mediante tais pressupostos, o presente artigo tensiona de que maneira a obra de autoria anônima e marco da ficção histórica (WEINHARDT, 2011) no México pode contribuir na problematização dos estudos dos polissistemas arrolado por Even-Zohar (1978), sublinhando certas linhas de força nos estudos literários que acabaram, por muito tempo, escamoteando a recepção deste romance para a recepção e ampliação do diálogo latinoamericanista.

Para tanto, far-se-á necessária uma breve apresentação de Xicoténcatl, elegendo as suas linhas-mestras para a construção da diegese, apresentando, a posteriori, alguns dos elementos que acabaram constituindo a prática tradutória para o português brasileiro. Logo, a seção seguinte procurará estabelecer um panorama sincrônico possível para as reflexões a respeito dos polissistemas nos estudos da tradução, viabilizando o entendimento desta leitura e a perspectiva crítica adotada pelos responsáveis para demonstrar de que maneira tal romance se constitui enquanto referência para futuros estudos. E, por último, ganhará destaque uma breve incursão para a leitura da ressignificação da personagem de extração histórica Hernán Cortés, procurando exemplificar como o plano ficcional acaba se constituindo enquanto espaço de potência para vias de descolonização do pensamento e do saber (SOUSA SANTOS, 2010; QUIJANO, 2014).

\section{Xicoténcatl: o primeiro romance histórico latino-americano e uma tradução do entrelugar}

Xicoténcatl (1826) é uma das obras fundamentais ${ }^{6}$ para a compreensão da formação da consciência crítica latino-americana produzida dentro da literatura no continente. Nesse sentido, há evidências, já a inícios do século XIX, na sua diegese, de características que a identificam como produto absorvido do processo antropofágico cultural, resultado de um exercício discursivo de transculturação (RAMA, 2008). Logo, corroboramos, com base nesse romance,

\footnotetext{
${ }^{6}$ Duas obras essenciais para a compreensão da formação da história literária na América Latina e de como se deu a escrita crítica latino-americana, já desde seus primeiros frutos é o primeiro romance latino-americano $E l$ Periquillo Sarniento (1816), de José Joaquín Fernández de Lizardi e o primeiro romance histórico latinoamericano, o anônimo, Xicoténcatl (1826). Del Pozo González (inédito), sob orientação de Gilmei Francisco Fleck, desenvolve a tese em andamento: Tradução de El Periquillo Sarniento (1816) - de José Joaquín Fernández de Lizardi ao português brasileiro e um estudo sobre o primeiro romance latino-americano, a ser defendido em 2023.
} 


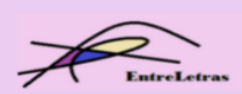

REVISTA ENTRELETRAS (ARAGUAÍNA), V. 12, N. 3, SET./DEZ. 2021 (ISSN 2179-3948 - ONLINE)

que o escritor latino-americano absorve aquilo que lhe interessa e o restante descarta para, a partir desse ponto, conceber a sua proposta literária.

Entendemos que Xicoténcatl (1826) é um romance elaborado com base no paradigma scottiano, porém, não se configura, de acordo com os estudos de Fleck (2017), como um romance histórico clássico ou tradicional, ambas modalidades possíveis na formação da fase acrítica. A diegese eliminou o uso dos dois fios narrativos utilizados por Scott, o secundário, que servia de pano de fundo histórico, e o principal, o fio puramente ficcional na qual se tecem as ações principais, e o simplificou apenas apresentando um único fio que segue a historiografia. Utiliza personagens de extração histórica ${ }^{7}$ que passam a ser o foco principal da diegese junto à possibilidade de interagir com personagens puramente ficcionais no mesmo plano. A obra não é um romance histórico escrito com a perspectiva de enaltecer o registrado nos anais da história, tudo o contrário, dando vazão a críticas e permitindo o confronto de discursos. Tudo isso remete-nos ao entre-lugar, o jogo paródico de "brincar com os signos de um outro escritor, de uma outra obra", postulado por Santiago (2000, p. 21) a inícios da década de 1970.

Dentre as características consideradas como antropofágicas podemos mencionar, também, o próprio título da obra. Xicoténcatl é o nome que alude diretamente à personagem de extração histórica, do mesmo nome, que a história hegemônica registrou como traidor da causa "conquistadora" por se opor abertamente aos planos de Hernán Cortés, quem, juntamente com sua pequena hoste, conseguiu submeter o Império Asteca e os outros povos nativos da região. Desse modo, a obra apresenta a perspectiva do vencido na sua diegese, pois relata e ressignifica todos aqueles registros feitos dos fatos acontecidos. O herói, nesta obra, é o vencido Xicoténcatl, o jovem, da nação tlaxcalteca, enquanto que o anti-herói é Cortés (costumeiramente enaltecido à patente de conquistador pelo discurso historiográfico até as propostas críticas e revisionistas da Nova História). A escolha do título do romance pelo nome de um herói de extração histórica - ao contrário do herói mediano utilizado no paradigma scottiano, a configuração concedida a Xicoténcatl é a do herói clássico com o intuito de exaltar ainda mais tudo o referente às sociedades nativas antes da chegada de Colombo - já aponta, a modo de advertência inicial, o processo crítico e de transculturação do qual o romance anônimo seria protagonista no então horizonte romântico finissecular.

\footnotetext{
7 De acordo com Trouché (2006, p. 44), o termo "narrativa de extração histórica" utiliza-se para referenciar ao "conjunto de narrativas que encetam o diálogo com a história, como forma de produção de saber e como intervenção transgressora [...]." A partir desse dado, transpomos o termo "extração histórica" para referenciar as personagens que são elaboradas dentro da ficção, mas com base histórica.
} 


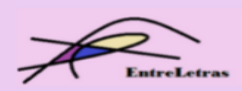

REVISTA ENTRELETRAS (ARAGUAÍNA), V. 12, N. 3, SET./DEZ. 2021 (ISSN 2179-3948 - ONLINE)

Para complementar a façanha problematizadora dos registros históricos, o narrador heterodiegético utiliza trechos inteiros do documento escrito pelo cronista oficial do Império espanhol do século XVII, Antonio de Solís, Historia de la Conquista de México (1632). Os trechos do documento oficial são facilmente identificados na diegese pelo leitor, pois, ao longo da leitura do texto, as citações diretas foram mantidas em itálico nas edições de 1964, 1995, 2012, na língua castelhana, e em $2020^{8}$, na primeira tradução ao português brasileiro. Ao utilizar os registros oficiais, a diegese põe em evidência a verossimilhança do relato enquanto que, ao mesmo tempo, revela seu discurso contestatário da historiografia. Dessa forma, essa obra não se configura como um texto apologético do discurso europeu oficializado nas crônicas.

Outra característica a ser apontada no primeiro romance histórico latino-americano é que já se exalta a partir dele o desejo de se efetivar um projeto nacional mexicano (segue a esperada verve hispanofóbica que poderia existir naquele momento). A este respeito, Forero Quintero (2012), inclusive, levanta, nos seus estudos, a existência da formulação da tese do destino manifesto da nação mexicana. Ainda que a diegese esteja contextualizada no processo de lutas pela tomada de Tenochtitlán, capital do Império Asteca, a leitura, em vários momentos, instiga o leitor contemporâneo ao contexto de publicação da obra para refletir sobre sua condição de colonizado no século XIX e mostra-lhe caminhos para optar pela necessidade de independência do Império espanhol. Por esse motivo, com o intuito de corroborar a necessidade de união de forças entre os cidadãos mexicanos do século XIX, a diegese relata, à maneira de espelho, como a divisão de forças entre os habitantes nativos americanos no século XVI durante as primeiras incursões dos europeus permitiu que o pequeno grupo de espanhóis fosse capaz de tomar Tenochtitlán. O discurso da obra, portanto, insta aos seus leitores do século XIX a participar unificada e ativamente em favor das lutas pela independência.

Para essa finalidade, em primeiro lugar, o narrador usa um vocabulário específico para exaltar a descrição da nação nativa principal na diegese, no caso, Tlaxcala. Utilizará termos que aludem à ideia de civilização, tais como: república, senado, congresso, cidadãos, soberania, nacional, nobre, bravo, poderoso, esplêndido, entre outros. Tlaxcala, nesse contexto, é elevado a modelo de nação e civilidade a ser seguida. Em contrapartida, para a configuração das personagens de extração histórica que se circunscrevem à realidade europeia restam termos que as rebaixam, atribuindo-lhes a ideia de barbárie, tais como: vândalos, bárbaros semisselvagens, covis, ingrato país, ambição, mercenários, tirano soberbo, intrigas, ambiciosos, entre outros etc.

\footnotetext{
${ }^{8}$ Para realizar nossos estudos, acessamos as edições de 1964 de Antonio Castro Leal, de 1995 de Luis Leal e Rodolfo J. Cortina, de 2012 de Gustavo Forero Quintero e de 2020, a primeira tradução ao português, por Gilmei Francisco Fleck.
} 


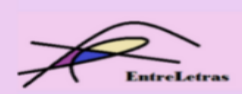

REVISTA ENTRELETRAS (ARAGUAÍNA), V. 12, N. 3, SET./DEZ. 2021 (ISSN 2179-3948 - ONLINE)

Em segundo lugar, o narrador estabelece duas forças antagonistas, uma contrária aos avanços dos europeus, sob a liderança de Xicoténcatl o jovem, seu pai, o velho Xicoténcatl e Teutila, a mulher nativa cônjuge do jovem Xicoténcatl, representante da beleza natural americana e guardiã da cosmovisão indígena. Do outro lado está o grupo de vilões, liderado por Hernán Cortés, Frei Bartolomé e os nativos Magizcatzin e dona Marina, nome espanhol da Malinche ${ }^{9}$ utilizado no romance. Diego de Ordaz, em contrapartida, é o único espanhol apontado como impoluto, leal, amigo sincero do jovem Xicoténcatl. Desse modo, verificamos um equilíbrio na contagem de forças, pois há tanto nativos quanto espanhóis em ambos os lados antagônicos.

No final, para continuar a seguir os registros do discurso historiográfico, a diegese relata a morte de Xicoténcatl, que acaba caindo nas armadilhas arquitetadas por Cortés. Igualmente, seu pai falece e não deixa um digno sucessor no senado tlaxcalteca. Logo, nos últimos capítulos, Teutila fracassa em sua vingança e também morre. Aqueles últimos acontecimentos no relato levam a dona Marina, depois de ganhar o filho de Cortés, a uma transformação radical, pois arrepende-se de ajudar na empreitada espanhola e decide retornar epistemologicamente para sua cultura nativa e defender a pureza dos costumes e crenças americanas. Assim, declara não desejar ser mais a cúmplice do estremenho. Tais ações auxiliam ao fechamento da configuração circular que o narrador lhe adjudica no tecido escritural. Essa nova postura nela a eleva e recebe o título de mãe simbólica da nação mestiça mexicana. Verificamos que esse é o modo como a diegese foi projetada para explicar que não há possibilidade de voltar ao passado indígena, pois não é mais viável viver sob a cosmovisão nativa. Cabe, nesse momento, a adaptação, com Malinche como a representante desse novo mundo mestiço. Com ela são aceitas todas as implicações de ter as culturas nativas e a europeia na formação da nova nação.

Todas as particularidades mencionadas nessa seção respondem por que Xicoténcatl (1826) não se configura como mais um romance histórico clássico e a impossibilidade de

\footnotetext{
${ }^{9}$ Cypess (1991), Herren (1993) e González Hernández (2002) concordam em afirmar que Xicoténcatl (1826) ao apresentar pela primeira vez configurações para as personagens históricas do nosso contexto serve de inspiração para outros romances de corte romântico nas quais Malinche recebe a configuração ou da donzela apaixonada por Hernán Cortés, ou de, por outro lado, a mulher pérfida, o monstro sexual, a intrigante e venenosa, La Chingada, em contraposição à Virgem de Guadalupe. Lembrando que a personagem histórica Malinche no romance é configurada a modo de servir de instrumento para o narrador justificar a sua tese. Cypess (1991, p. 43 - Nossa Tradução), por outro lado, expõe que o historiador mexicano Edmundo O'Gorman (1906-1995) afirma que muitos historiadores mexicanos da primeira metade do século XIX acreditaram que a desordem e ruína econômicas e o caos administrativo do período da pós-independência mexicano se devia a uma interferência estrangeira maligna que O'Gorman chama de teoria do bode expiatório: o mito da Malinche. Desse modo, a personagem mitificada carrega um lado positivo e outro negativo, pois ela passa a ser considerada como "la Eva-Malinche en palabras de Sonia Montecino, y [...] la 'madre y puta, traidora y útero simbólico de la nación mexicana' en la conocida frase de Fernanda Núñez Becerra." [Nossa Tradução: segundo as palavras de Sonia Montecino: a Eva-Malinche, e, [...] a 'mãe e puta, traidora e útero simbólico da nação mexicana' segundo a conhecida frase de Fernanda Núñez Becerra] (MARTIN, 2007, p. 11).
} 


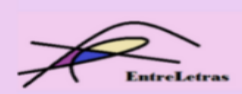

REVISTA ENTRELETRAS (ARAGUAÍNA), V. 12, N. 3, SET./DEZ. 2021 (ISSN 2179-3948 - ONLINE)

enquadrá-lo dentro do conjunto dos romances históricos tradicionais. Depois da sua publicação, não houve nenhuma reflexão crítica que sublinhasse todas as características mencionadas. Os autores apenas adotaram o único fio narrativo e continuaram a escrever textos laudatórios da história hegemônica europeia, produzindo apenas romances históricos tradicionais. Portanto, a obra anônima é um romance de ruptura, já que fissura o esquema scottiano e não chega a configurar um modelo de escrita decorrente, pois somente obras latino-americanas com esse teor crítico poderiam ser lidas novamente após o período de surgimento do novo romance histórico latino-americano ${ }^{10}$.

Nesse sentido, admira, pela importância das teses postuladas e pelo novo paradigma escritural proposto em Xicoténcatl (1826), que tenha prevalecido a ausência de interesse em traduzir a obra por parte dos tradutores brasileiros. O público leitor brasileiro teve de aguardar, desde 1826 até o ano de 2020, pela tradução do romance. A intencionalidade de eleger especificamente uma obra para ser traduzida, de acordo com Fleck (2020), está relacionado com o desejo de levar ao público leitor da língua portuguesa não apenas uma obra romanesca, mas, evidenciar as visões críticas da obra, sua relevância tanto no seu contexto de produção quanto como obra que conduz ao leitor de hoje como via de descolonização.

Even-Zohar (1978) e Gentzler (2001), cujas teorias serão comentadas na seção seguinte, auxiliam-nos no entendimento de como um polissistema literário ainda em formação, como o brasileiro, teria sido beneficiado caso a tradução dessa obra oitocentista viera à luz anteriormente. Sem dúvida, a tradução do Xicoténcatl (1826), ainda no século XIX, teria mudado a história dos paradigmas de escrita da nossa literatura (DEL POZO GONZÁLEZ, inédito). No entanto, naquele contexto, o Brasil esteve sob estrita vigilância das autoridades portuguesas para prevenir a formação crítica dos jovens cérebros oitocentistas (LAJOLO; ZILBERMAN, 1998). Houve, sim, incentivo para traduzir literatura estrangeira, como o comprova a tradução do romance Le Capitaine Paul (1843), de Alexandre Dumas, publicada no Brasil no mesmo ano da sua publicação na França (BEZERRA; GIMÉNEZ, 2019). No entanto, acreditamos que naquele contexto as instâncias reguladoras da monarquia não deixariam passar um texto com o teor crítico de Xicoténcatl (1826).

\footnotetext{
10 O Novo Romance Latino-Americano - NRL, movimento literário que destaca as produções latino-americanas pela sua importância e impacto na literatura mundial, que deu início ao Boom, teve seu ápice na década de 1970. Dele faz parte o Novo Romance Histórico Latino-Americano - NRHL. Conforme Aínsa (1991, p. 11), o NRHL atua com liberdade para reler e reescrever a historiografia, pois "[...] la nueva narrativa, a través de un deliberado revisionismo relee y reescribe esa historia, oficial, desde el diario de Colón, crónicas y relaciones, hasta textos contemporáneos como los de la revolución mexicana." [Nossa Tradução: [...] a nova narrativa, através de um deliberado revisionismo, relê e reescreve essa história, oficial, desde o diário de Colombo, crônicas e relações, até textos contemporâneos como os da revolução mexicana.].
} 


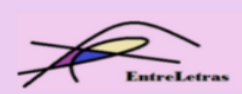

REVISTA ENTRELETRAS (ARAGUAÍNA), V. 12, N. 3, SET./DEZ. 2021 (ISSN 2179-3948 - ONLINE)

Por outro lado, agora, já na entrada da segunda década do século XXI, é imperativo refletir sobre quais motivações livros desse valor teórico, crítico, histórico e literário ainda não receberam a atenção das editoras, ou dos tradutores em última instância. Contudo, o contexto acadêmico dos grupos de pesquisa nas universidades tornam-se as únicas vias que patrocinam esse grupo de obras basilares pelo seu teor crítico.

Entendemos, nesse sentido, a importância do espaço de pesquisa universitário, em palavras de Palermo (2018), lugares de reflexão transmoderna, lugares da geração de saberes. Para confluir com essa idealização, é necessária a atuação de tradutores cientes das relações de poder no texto (ÁLVAREZ; VIDAL, 1996) e das transferências interculturais nada inocentes no processo tradutório. Lefevere (1994, p. 12), a respeito, afirma que “[...] translation is indeed acculturation. ${ }^{11}$ " Desse modo, é indispensável que o tradutor saiba se posicionar diante das forças no texto de estar ciente da sua responsabilidade, ele/ela preferirá evitar aculturar o texto, sem ocultar nem maquiar aquilo que talvez não seja palatável para o leitor meta.

A nova fidelidade do tradutor encontra-se em que deverá saber evidenciar essas forças de poder e cuidar, também, como comunicar esse conteúdo para evitar o silenciamento de vozes. O tradutor latino-americano, ciente do seu papel, é um tradutor do entre-lugar que se assume como ser não puro, que propõe-se a traduzir obras de interesse para nosso contexto (CERDEIRA; DEL POZO GONZÁLEZ; FLECK, 2021, inédito).

\section{Polissistema: um panorama sincrônico possível e o nosso tensionamento para pensar a tradução do primeiro romance histórico latino-americano}

Para refletir a respeito da relevância para o pretérito e da potencialidade do discurso de Xicoténcatl (2020), é necessário não “decifrar” o seu significado, mas deslindar o modo pelo qual normas e modelos foram aceitos, adaptados, contestados ou mesmo subvertidos, no interior do polissistema americano. Trata-se, assim, de uma perspectiva epistemológica ao tomar ambos Xicoténcatl a partir de suas idiosincrasias discursivas, seja no contexto hispano-americano, seja na recepção de lusófonos, ponderando sobre a necessidade de (des)colonizar certos saberes, reinventando (novos) poderes (SOUSA SANTOS, 2010).

Sendo assim, torna-se importante consignar que os processos de "descoberta", "invasão", "conquista" e "dominação" da América iniciados em 1492 não somente solaparam as estruturas das civilizações locadas no continente como também estabeleceram as diretrizes

\footnotetext{
${ }^{11}$ Nossa Tradução: [...] tradução é, de fato, aculturação.
} 


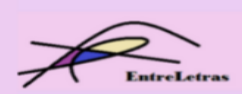

REVISTA ENTRELETRAS (ARAGUAÍNA), V. 12, N. 3, SET./DEZ. 2021 (ISSN 2179-3948 - ONLINE)

de uma nova forma de controle global: a colonialidade. Segundo Quijano (2014), tal movimento discursivo implicou e se constituiu, em um de seus ângulos, por meio da reclassificação da população do planeta, da instituição de um aparato de Estado responsável por administrar as suas categorizações e da implementação de espaços voltados para a execução desses fins. Para justificar a realização dos atos perpetrados, houve, por parte dos colonizadores, ainda, a adoção de uma epistemologia capaz de conferir sentido e função à produção de conhecimento, na nova rede de poder estabelecida.

Em decorrência da violência epistêmica cometida com relação às outras gnosiologias locais, as atividades consideradas fundamentais nos ambientes centrais, como o pensamento, a crítica, a leitura e, inclusive, a escritura, foram vedadas aos "descobertos". Tal condição deuse, pois, conforme Fleck (2018, p. 33),

$\mathrm{Na}$ América Latina, a trajetória da leitura e da escrita está estritamente vinculada a tudo o que representou o processo de colonização: dominação, imposição, exploração, subjugação. No nosso continente, colonizado pela Europa, aproveitou-se do poder da palavra escrita somente uma pequena porcentagem da elite dominante, sempre em função de manter a estratificação social que deu origem às nações latino-americanas.

Tal cenário de silenciamentos, exclusões e apagamentos acarretou a estabilização de um dos três traços do que Rama (1974, p. 47) denominou de o comportamento cultural latinoamericano, "a forma de apropriação das culturas estrangeiras [...], própria de um continente dotado de estrutura econômica dependente.” Segundo a síntese de Nitrini ([1997] 2015, 77), essa característica corresponderia à "assimilação de uma literatura estrangeira recebida como um legado e que tinha o estatuto de um paradigma". Em outras palavras, a conjuntura da escritura latino-americana e, portanto, mexicana, por causa da injunção colonial, tornou-se, não completamente, mas majoritariamente, subordinada às normas e modelos postos em circulação pelas metrópoles, mesmo após o período em que as suas nações independentizaram-se politicamente.

Constatamos, portanto, que os textos consoantes à cultura eurocêntrica se encontraram, por motivos sócio-históricos e não somente estéticos, nas posições privilegiadas do que EvenZohar (1978) denominaria de a rede de sistemas literários e extraliterários das sociedades americanas. Na nossa parte do continente, o núcleo de tal polissistema foi, inicialmente, ocupado pelas produções canônicas do Velho Mundo, a única aceita pelas coroas espanhola e portuguesa, que mantiveram o controle da publicação dos romances durante o período em que exerceram o comando político dos territórios. Depois da independência, foram as traduções de folhetins franceses ou ingleses, por exemplo, que passaram a servir como sustentáculo dessa 


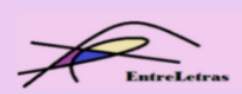

REVISTA ENTRELETRAS (ARAGUAÍNA), V. 12, N. 3, SET./DEZ. 2021 (ISSN 2179-3948 - ONLINE)

literatura em formação. Se incluirmos no escopo da análise a América anglófona, outro elemento assoma-se, embora não mude o quadro ideológico estabelecido: a emergência da fase acrítica do romance histórico, nos Estados Unidos da América. Segundo Fleck (2017), com base na receita scottiana, escritores renarrativizaram os discursos oficializados pela história hegemônica, com o objetivo de construir uma identidade patriótica aos moldes europeus, elaborando, assim, os mitos que serviram de base e justificação às suas ações imperialistas, subsequentemente.

Ao realizar o mesmo processo lógico, porém de maneira inversa, verificamos que as produções orais e escritas daqueles que foram emudecidos pelo poder colonial preencheram, em uma metáfora tópica aos moldes de Even-Zohar (1978), os arrabaldes do polissistema americano. Não obstante, como Rama (1974) também indicou a respeito do comportamento cultural latino-americano, tais momentos de dependência foram intercalados por outros, em que súbitas irrupções liminares fizeram circular visões distintas. Nesse cenário, alguns dos assim escritores de romance histórico românticos foram preponderantes. Especificamente no caso mexicano, esses poucos romancistas, “[...] para quienes era imperante la revisión del pasado, sobre todo, porque existía la necesidad de crear una identidad como nación independiente. ${ }^{12 "}$ (GUTIÉRREZ LÓPEZ, 2017, s/p), efetuaram uma releitura dos registros dos colonizadores, concebendo, para isso, um hibridismo tanto da forma (isto é, entre a história e a ficção), quanto do teor ideológico (ou seja, entre as tradições indígenas, crioulas e, às vezes, africanas).

Dentre as escrituras que se enquadram na discussão estabelecida por Gutiérrez López (2017), Xicoténcatl foi crucial por ser, além de o primeiro romance histórico latino-americano, uma das únicas obras de seu gênero a projetar, do exterior do projeto colonial/moderno, no instante mesmo dos embates anticoloniais, imagens atravessadas por um teor crítico com relação às histórias imperiais/modernas europeias e às coloniais americanas. É significativo ressaltar, como mencionado anteriormente, o fato de que a forma fomentada por sua diegese não se estabilizou, dando origem a um protótipo replicado por outros imitadores, tal qual ocorreu com a modalidade clássica scottiana do romance histórico, rearticulada por James Fenimore Cooper (1789-1851), nos Estados Unidos, ou a modalidade tradicional, nos séculos XIX e XX. Com efeito, o posicionamento do texto mexicano no polissistema continental da primeira metade do século foi singular.

\footnotetext{
${ }^{12}$ Nossa tradução livre: [...] para quem era imperante a revisão do passado, sobretudo porque existia a necessidade de criar uma identidade como nação independente." (GUTIÉRREZ LÓPEZ, 2017, s/p).
} 


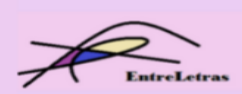

REVISTA ENTRELETRAS (ARAGUAÍNA), V. 12, N. 3, SET./DEZ. 2021 (ISSN 2179-3948 - ONLINE)

Para expressar a heterogeneidade das estruturas descritas, utilizamos os preceitos difundidos por Even-Zohar (1978) acerca das correlações assentadas entre os sistemas literários. Enquanto a noção do sistema foi forjada para compreender "the relationship of the innovative formal element to the specific text and to the existing literary order. ${ }^{13}$ " (GENTZLER, 2001, p. 115), a do polissistema serviu para incluir ao constructo "the literary, semi-literary and extraliterary structures. ${ }^{14 "}$ (GENTZLER, 2001, p. 115). Além disso, com a finalidade de evidenciar as relações hierárquicas que os sistemas mantêm entre si, Even-Zohar (1978, p. 16) postulou a ideia de que "some maintain a more central position than others, or that some are primary while others are secondary. ${ }^{15 "}$ A figura a seguir, feita com base na interpretação de Flórez Petour (2014) e Santos (2018) da teoria do polissistema, ilustra, então, os tensionamentos sistêmicos (entre espaços primários e secundários) nos quais Xicoténcatl encontrou-se, segundo uma possível interpretação das fricções sistêmicas:

Figura 1 -- Diagrama dos polissistemas latino-americano e estadunidense

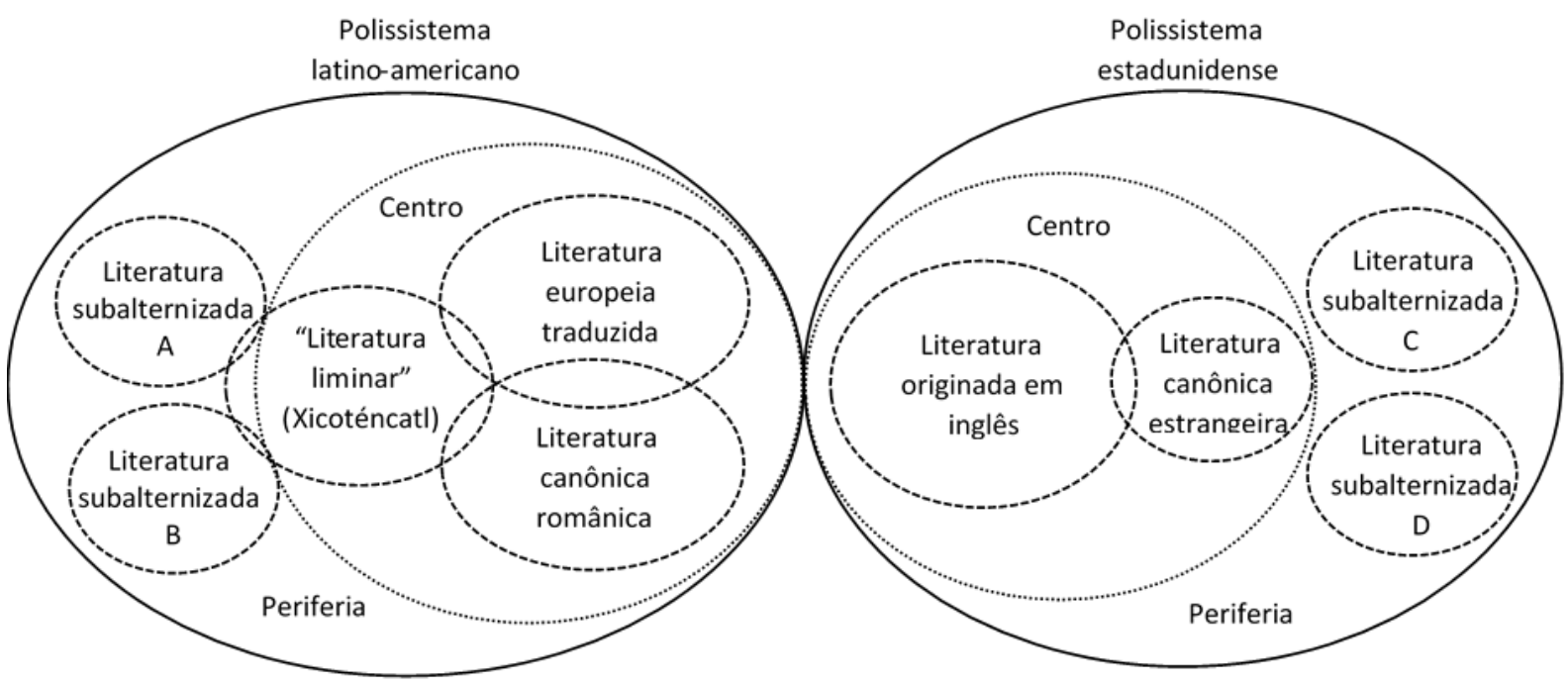

Fonte: elaborado pelos autores (2021)

No esquema, a literatura canônica românica ${ }^{16}$ (ou a nacional, mas determinada por essa) e a não-românica traduzida desempenharam a função de primárias, no polissistema latinoamericano. No caso estadunidense, o mesmo papel foi assumido pela literatura nacional, que

\footnotetext{
13 Nossa tradução livre: "a relação do elemento formal inovativo com relação ao texto e à ordem literária existente." (GENTZLER, 2001, p. 115).

${ }^{14}$ Nossa tradução livre: "as estruturas literárias, semiliterárias e extraliterárias.” (GENTZLER, 2001, p. 115).

15 Nossa tradução livre: "alguns mantêm uma posição mais central do que outros ou que alguns são primários enquanto outros são secundários.” (EVEN-ZOHAR, 1978, p. 16).

${ }^{16}$ Henríquez Ureña (1928) utilizou o termo para se referir às influências neolatinas da América Latina.
} 


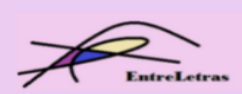

REVISTA ENTRELETRAS (ARAGUAÍNA), V. 12, N. 3, SET./DEZ. 2021 (ISSN 2179-3948 - ONLINE)

buscou efabular um mito ufanista, e pela canônica anglosaxã, importada da Europa. Em ambos os polissistemas, as literaturas subalternizadas (frequentemente colocadas para fora do sistema literário) foram postas à margem, como secundárias. Como é possível observar pela Figura, Xicoténcatl localizou-se, por sua vez, na interseção do literário e do extraliterário, do central e do periférico, do subordinante e do subalternizado, e, precisamente por essa razão, entre a repetição e a diferença, entre a transcrição e a inovação, entre o apográfico e o original.

Como vimos, a raíz da circunscrição do romance nesse entroncamento polissistêmico encontra-se na constituição de um entre-lugar que se perfaz em seu discurso narrativo. Nele, tanto a história e a memória dos marginalizados, quanto as contabilizações coloniais oficializadas são recuperadas. Todavia, no jogo com as palavras dos outros, "o texto segundo se organiza a partir de uma meditação silenciosa e traiçoeira sobre o primeiro texto" (SANTIAGO, 2000, p. 20). O romancista anônimo faz, consequentemente, avançar uma transgressão ardilosa do material histórico amplamente conhecido, uma agressão ao código e às fórmulas acríticas prestigiados nos assim denominados “centros”, por Even-Zohar (1978), uma rebelião com relação à ideologia perpetuada pelo poder e uma expressão das vozes daqueles que não puderam ser ouvidos. Mediante a configuração de tal devoração crítica do documento/monumento histórico, ele antecipou em mais de um século, portanto, as escrituras que, a partir da pluralidade de tradições culturais, buscaram novas visões de "nuestra literatura, incorporándola a las corrientes de vanguardia y al enfrentamiento con la realidad del latinoamericano. ${ }^{17}$, , como indicou a professora Mora Villamizar (2020, p. 185) sobre a nova narrativa.

Assim como adiantou as imagens que apareceram somente com o boom, a obra também poderia se associar a um segundo campo, mencionado por Santiago (2000): “A literatura latinoamericana de hoje nos propõe um texto e, ao mesmo tempo, abre o campo teórico em que é preciso se inspirar durante a elaboração do discurso crítico de que ela será o objeto.” (SANTIAGO, 2000, p. 26) e meio.

Por intermédio dessa intercessão, tomamos os enfrentamentos que Xicoténcatl perfez de encontro aos registros tradicionais que efabularam os conflitos travados na América pelos tlaxcaltecas e de todo o imaginário colonial/moderno, em 1826, como um ponto de inflexão tanto para o percurso da escritura do romance histórico quanto para os saberes que atravessam as práticas teóricas e discursivas dos intelectuais que habitam o entre-lugar do discurso latino-

\footnotetext{
17 Nossa tradução livre: "nossa literatura, incorporando-a às correntes de vanguarda e ao enfrentamento com a realidade do latino-americano." (MORA VILLAMIZAR, 2020, p. 185).
} 


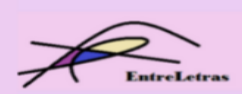

REVISTA ENTRELETRAS (ARAGUAÍNA), V. 12, N. 3, SET./DEZ. 2021 (ISSN 2179-3948 - ONLINE)

americano. A incorporação desses "outros" horizontes possíveis, sugestionados pela releitura que somente um corpo ficcional foi capaz de produzir no momento "final" da subjugação, poderia provocar a constituição de um saber decolonial e de "una universidad que quiebre con el modelo hegemónico imperante desde su aparición en América Latina [...], buscando el des-prendimiento de la colonialidad epistémica que implica. ${ }^{18 "}$ (PALERMO, 2010, p. 44). Ademais, na medida em que a colonialidade ocupa lugares, a retomada de um discurso liminar, máxime no caso da tradução de uma obra como Xicoténcatl para o espaço brasileiro, causa uma transformação no polissistema, inversamente proporcional a que a gramática de Nebrija fizera, por exemplo, com a sedimentação da unidade linguística hispanoamericana. Armada de tal arsenal, a crítica que se interpõe nessa encruzilhada pode, por conseguinte, caminhar de acordo com uma proposta consciente de seu lugar na geopolítica do saber, ou, como planejou Palermo (2011b, p. 128-9), nos passos de um regionalismo crítico, que tende

a revertir ese estado de cosas en estos días en los que pertenencias e identidades se definen ya no por la radicación en una nación, o lengua o raza, sino por la actualización de genealogías diversas de las que se constituyeron, no para "recuperar" un pasado originario y puro, sino [para recuperarlo] en sus contaminaciones, olvidos, y entrecruzamientos "fronterizos". 19

\section{Hernán Cortés: a desconstrução de uma historiografia positivista protagonizada pela}

\section{ficção}

Tal como dito na seção anterior, ainda que não tenha representado a produção majoritária do romance histórico no contexto hispano-americano na primeira metade do século XIX, é relevante como Xicoténcatl (1826) pode se transformar em uma espécie de pedra-detoque para futuros estudos, seja para os investigadores dedicados à reflexão das fases e modalidades deste gênero de escrita híbrida, seja para aqueles filiados diretamente aos estudos da tradução. Aqui, nesta leitura, a obra de autoria anônima é selecionada para valorizar o que lhe cabe enquanto produção iluminadora de um determinado polissistema, auxiliando, posteriormente, a consolidar o que já assinalamos enquanto pensamento liminar.

O fato de que a obra tenha sido apresentada ao público lusófono, em português brasileiro, pouco mais de dois séculos após a sua publicação original, abre um capítulo distinto

\footnotetext{
${ }^{18}$ Nossa tradução livre: "uma universidade que quebre com o modelo hegemônico imperante desde a sua aparição na América Latina [...], buscando o desprendimento da colonialidade epistêmica que implica." (PALERMO, 2011a, p. 44).

${ }^{19}$ Nossa tradução livre: "a reverter esse estado de coisas nestes dias em que pertencimentos e identidades já não se definem mais pela radicação em uma nação, língua ou raça, mas pela atualização de genealogias diversas que se constituíram não para 'recuperar' um passado originário e puro, mas para [recuperá-lo] em suas contaminações, esquecimentos e entrecruzamentos 'fronteiriços'." (PALERMO, 2011b, p. 128-9).
} 


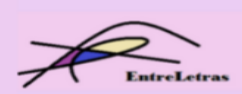

REVISTA ENTRELETRAS (ARAGUAÍNA), V. 12, N. 3, SET./DEZ. 2021 (ISSN 2179-3948 - ONLINE)

para a discussão de como a prática tradutória acaba expandindo os limites de ditas literaturas nacionais e, principalmente, se constituindo enquanto expressão do discurso a partir do entrelugar que nos caracteriza a todos da América Latina.

A essa altura, é provável que os leitores que ainda não tenham lido a tradução deste romance histórico se perguntem como, a partir da arte literária, estão (des)construídos certa moral de um tempo-espaço, o horizonte monológico que, por muito, acabou caracterizando parte das historiografias voltadas a narrar o processo de chegada e de invasão europeia. Como sublinhado na primeira seção deste artigo, o eixo nodal de toda a narrativa está baseada na ambientação do domínio e da derrocada do antigo império asteca por parte da figura de extração histórica Hernán Cortés e dos seus seguidores.

Em Xicoténcatl, a escolha por ficcionalizar Cortés dinamita qualquer imaginário laudatório do discurso dos vencedores. No romance, a figura de Cortés é permeada de ambiguidades e humanidades, encarnando, de maneira geral, a função de anti-herói ou de polo reverso da moral e dos valores personificados pelo guerreiro Xicoténcatl ou mesmo por seu pai, uma das figuras centrais da construção política dos tlaxcaltecas. Ambicioso e porta-voz da soberba característica daqueles que usam semanticamente o valor da descoberta como uma escusa para a prática de diferentes atrocidades, a personagem Hernán Cortés é construída pouco a pouco, assume um caráter circular e demonstra não ser simplesmente um antagonista plano, alguém disposto a exercer uma vilania banal. Muito ao contrário, este Cortés assusta justamente pelos contornos dados pela ficção: "Cortés não era do tipo de homem que vacila em suas decisões" (ANÔNIMO, 2020, p. 131), era dono de "caráter orgulhoso e arrogante" (ANÔNIMO, 2020, p. 164), "nunca havia conhecido medo ou apreensão" (ANÔNIMO, 2020, p. 135).

A descrição, talvez, explique o fato de que o invasor espanhol tenha sido comparado “como um tigre feroz" (ANÔNIMO, 2020, p. 166). Diferentemente do que o leitor mais apressado pode supor, Xicoténcatl não busca simplificar a figura de Cortés em sua arquitetura, assinalando que o caráter de fera realmente prejudicial estava no fato de que Cortés era "político astuto" (ANÔNIMO, 2020, p. 172), "não era o tipo de homem que abandonava facilmente seus projetos" (ANÔNIMO, 2020, p. 143).

Por todo o tempo, Cortés personifica os riscos da descoberta, chancela como o "descobrir" ganhava novos significados aos olhos dos que aqui chegavam e tentavam escamotear a pluralidade das civilizações então vigentes. Ao final do Livro I, após reunir as tropas espanholas na saída de Jacacingo, Cortés toma a palavra para sentenciar: 


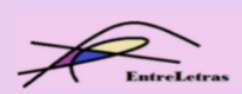

- Companheiros! Os tlaxcaltecas não responderam nossa mensagem. Oito dias se passaram desde que nossos embaixadores deixaram o acampamento, e uma semana já é demais para nossa paciência. Vamos nós mesmos descobrir a causa de sua demora. Companheiros! Tlaxcala será nossa amiga ou sofrerá a ira de Tabasco! (ANÔNIMO, 2020, p. 125).

Ao ressignificar a personagem de extração histórica heroicizada por parte do discurso historiográfico, o romance histórico estudado traz a discussão de uma moral pseudocivilizatória pouco afável e indisposta ao diálogo, criticando diretamente os princípios de expansão imperiais que caracterizam potências ultramarinas como a Espanha entre os séculos XV, XVI e XVII. Na arquitetura da diegese, é notável como o Livro II, segunda seção da obra, propõe o controle da narrativa, instituindo uma pontual analepse e recuo temporal em relação ao tempo do que é narrado, justamente para chamar a atenção do leitor e contextualizar um Cortés imoral, disposto às fraquezas humanas para ascender. Assim, ainda que dotado de "coragem única" e apresentado como "bravo soldado" (ANÔNIMO, 2020, p. 149), os leitores serão apresentados a alguém imprudente, capaz de ser preso pelo padrinho e governador, Diego Velázquez, justamente por apresentar um comportamento imprudente para com a sua futura esposa, dona Catalina Suárez de Pacheco.

O nível de criticidade do romance transcende à humanidade do soldado Cortés. A ironia está justamente ao enlaçá-la com a moral da fé instituída pela Igreja e pelos seus representantes. Cortés não é apenas uma figura isolada, mas está batizado pela cristandade de uma época - ou melhor, de uma colonialidade - que viu, em nome do Pai, do Filho e do Espírito Santo, justificativa para silenciar e assassinar: “Com a insurreição aberta de tal maneira, Hernán Cortés preparou suas tropas e, depois de celebrar uma missa ao Espírito Santo e de eleger a São Pedro como o patrono da armada, partiu, em 10 de fevereiro de 1519, em direção ao Cozumel.” (ANÔNIMO, 2020, p. 128).

Ainda sobre o aspecto de como a figura de Cortés é recuperada em Xicoténcatl para tensionar justamente a parte que lhe coube à Igreja pela desestruturação e consequente extermínio das civilizações que conformavam o universo asteca, é relevante resgatar um diálogo entre as personagens Diego de Ordaz e frei Bartolomé de Olmedo. Aquele, depois de ouvir este sobre a fidelidade dos reis espanhóis, questiona o representante da fé sobre o modus operandi de Cortés, decreta:

- Não há a menor dúvida de que os leais espanhóis sempre obedeceram a seus reis deste modo e assim também com a autoridade que deles demanda. 


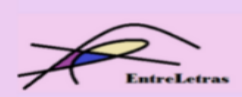

- Então, em outras palavras, se Hernán Cortés pervertesse certos pontos da fé, como o vimos fazer com os costumes, e nos ordenasse adorar um crocodilo, devemos obedecê-lo cegamente? (ANÔNIMO, 2020. p. 149).

Ao longo de toda a trama, a personagem de extração histórica será também o responsável por cooptar Doña Marina a enganar os seus e, assim, levar informações ao invasor. Ao interseccionar questões do discurso histórico com a trama novelesca (aqui ganha destaque a figura de Teutila justamente para o desenvolvimento da diegese), Xicoténcatl potencializa o caráter serpentário de Cortés, do invasor, fissurando ou oferecendo novos estudos sobre a simplificação da traição por parte de Malinche.

Será no final do romance, após um momentâneo estado de arrependimento e alumbramento de Cortés após perceber a morte de Teutila e ouvir Doña Marina, o invasor espanhol demonstrará a sua não redenção, potencializada pelo frei Bartolomé de Olmedo, ironicamente aquele que tinha a voz da fé e deveria personificar a comunhão, o perdão e a compaixão:

Este discurso produziu justamente o efeito contrário a que se propunha o bom religioso, pois afogou as fagulhas de terna sensibilidade que Marina havia acendido no coração de Cortés. E este, recobrando sua superioridade e tranquilidade costumeiras, levantou-se dizendo:

- Acabemos, amigos. Esta cena dolorosa já durou tempo demais. O caminho que conduz ao templo da fama tem grandes tropeços e, por isso mesmo, é tão glorioso vencê-los. Talvez seja mais doce viver tranquilo e sossegado em um canto, mas meu destino não é este. Amanhã partimos para o México. (ANÔNIMO, 2020, p. 247, negritas nossas).

O flerte ao titubear é ironicamente endossado pela narrativa ficcional a partir da voz da personagem de extração histórica, Hernán Cortés, convicta de que ao seu destino caberia não exatamente retroceder, mas, sim, protagonizar mais um capítulo da invasão sofrida por e em nossa América.

\section{Considerações finais}

Após a espera de quase dois séculos, entre o ano de publicação da obra original e a data do lançamento da obra traduzida ao português brasileiro, os leitores empíricos brasileiros podem encontrar em Xicoténcatl um novo capítulo não apenas para os estudos da tradução, mas, 


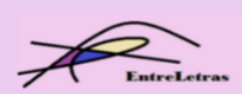

REVISTA ENTRELETRAS (ARAGUAÍNA), V. 12, N. 3, SET./DEZ. 2021 (ISSN 2179-3948 - ONLINE)

fundamentalmente, para entender como uma determinada obra acaba constituindo e, ao mesmo tempo, rompendo certas cadeias impostas pelos polissistemas literários.

No caso da obra de escrita híbrida estudada, passa a ser possível vislumbrar mais um interessante caminho para que seja possível reconfigurar saberes e demonstrar como a literatura se constitui enquanto entre-lugar do discurso latino-americano. A tradução desta obra anônima no Brasil certamente deixa em relevo uma proposta para todos os intelectuais que buscam ressignificar e construir vias para a descolonização.

\section{Referências}

AÍNSA, F. La nueva novela histórica latinoamericana. Plural, México, v. 240, p. 82-85, 1991.

ÁLVAREZ, R.; VIDAL, M. C. Translating: a political act. In: ÁLVAREZ, R.; VIDAL, M. C. (Ed.). Translation power subversion. Philadelphia: Multilingual matters, 1996.

ANÔNIMO. Xicoténcatl: o primeiro romance histórico latino-americano. Tradução de Gilmei Francisco Fleck. Curitiba: CRV, 2020. 266 p.

BEZERRA, V. C.; GIMÉNEZ, P. R. Aspectos da repercussão de Alexandre Dumas no Brasil: o romance-folhetim e a ficção nacional. Revell. v. 1, n. 21, p. 231-255, 2019. Disponível em: https://periodicosonline.uems.br/index.php/REV/article/view/3374/pdf. Acesso em: 26 jan. 2021.

CERDEIRA, P. de L. Argentum Córdoba: diálogos, fissuras e soslaios entre ficção e história sob as miradas de Cristina Bajo, Andrés Rivera e María Teresa Andruetto. 2019. 569f. Tese de Doutorado, Programa de Pós-graduação em Letras, Universidade Federal do Paraná, Curitiba, 2019.

EVEN-ZOHAR, I. Papers in historical poetics. 1. Ed. Tel Aviv: The Porter Institute for Poetics and Semiotics/Tel Aviv University, 1978.

FLECK, G. F. O romance histórico contemporâneo de mediação: entre a tradição e o desconstrucionismo - releituras críticas da história pela ficção. Curitiba: CRV, 2017.

FLECK, G. F. Introdução. In: LOPEZ, C. J. et al (orgs.). A pesquisa em literatura e leitura na formação docente: experiências da pesquisa acadêmica à prática profissional no ensino. 1. Ed. Campinas: Mercado de Letras, 2018.

FLECK, G. F. Xicoténcatl (1826): Cenário de rupturas e enfrentamentos com os ditames europeus do século XIX na América Latina. In: ANÔNIMO. Xicoténcatl: o primeiro romance histórico latino-americano. Tradução de Gilmei Francisco Fleck. Curitiba: CRV, 2020. p. 3346.

FLÓREZ PATOUR, M. T. Systems, ideologies and history: a three-dimensional absence in the study of assessment reform processes. Assessment in Education: Principles, Policy \& Practice, 


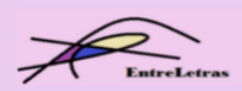

REVISTA ENTRELETRAS (ARAGUAÍNA), V. 12, N. 3, SET./DEZ. 2021 (ISSN 2179-3948 - ONLINE)

2015, v. 22, $\quad$ n. $\quad 1, \quad$ p. 3-26. Disponível em: http://ppgecpan.sites.ufms.br/files/2016/11/Art\%C3\%ADculo-Art-AfL-Three-dimensionalabsence-impreso.pdf. Acesso em: 30 out. 2021.

FORERO QUINTERO, G. Estudio preliminar. In: ANÓNIMO. Xicoténcatl. Edición, estudio preliminar y notas de Gustavo Forero Quintero. Madrid: Vervuert, 2012. p. 9-80.

GENETTE, G. Palimpsestos: a literatura de segunda mão. Tradução de Ciblele Braga et all. Belo Horizonte: Edições Viva Voz, 2010.

GENTZLER, E. Polysystem Theory. In: GENTZLER, E. Contemporary translation theories. 2. Ed. Great Britain: Cromwell Press, 2001. p. 106-144.

GUTIÉRREZ LÓPEZ, L. G. La novela en México en el siglo XIX. 1. Ed. Ciudad de México: Bonilla Artigas Editores/UAEM, 2017.

HENRÍQUEZ UREÑA, P. Seis ensayos en busca de nuestra expresión. 1. Ed. Buenos Aires: Babel, 1928.

LAJOLO, M.; ZILBERMAN, R. A formação da leitura no Brasil. 2.ed. São Paulo: Ática, 1998.

LEFEVERE, A. Translating literature. Practice and theory in a Comparative Literature contexto. Second printing. New York: The Modern Language Association of America, 1994.

LUKÁCS, G. La novela histórica. Tradução de Jasmin Reuter. México D.F.: Ediciones Era, 1966.

MARTÍ, J. Nuestra América. Disponible en:

http://bibliotecavirtual.clacso.org.ar/ar/libros/osal/osal27/14Marti.pdf Acesso em: 03 oct.

2021.

MARTÍN, M. T. D. Perspectivas historiográficas: mujeres indias en la sociedad colonial hispanoamericana. Frentes Avanzados de la Historia. Revista de difusión histórica interatlántica y de género/S- Investigación, genealogía profesional. Universidad Nacional de Educación a Distancia. UNED/España. 2007. Disponível em: http://maytediez.blogia.com/2007/022704-perspectivas-historiograficas-mujeres-indias-en-lasociedad-colonial-hispanoamer.php. Acesso em: 02 jan. 2015.

MORA VILLAMIZAR, D. Literatura latinoamericana: búsquedas de raíces, expresiones y resistencias. In: FLECK, G. F. et al (Orgs.). Imagens da América: representações, expressões, resistências. 1. Ed. Curitiba: CRV, 2020. p. 185-200.

NITRINI, S. Literatura Comparada: história, teoria e crítica. 3.ed. São Paulo: Editora da Universidade de São Paulo, 2015.

PALERMO, Z. La Universidad Latinoamericana en la encrucijada decolonial. Otros Logos, Revista de Estudios Críticos, Universidad Nacional del Comahue - Facultad de Humanidades/ Neuquén - Argentina, n.1, p. 43-69, dez./2010. Disponível em: http://www.ceapedi.com.ar/otroslogos/2010-1.htm Acesso em: 01 nov. 2021. 


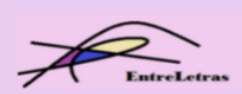

REVISTA ENTRELETRAS (ARAGUAÍNA), V. 12, N. 3, SET./DEZ. 2021 (ISSN 2179-3948 - ONLINE)

PALERMO, Z. Por qué vincular la Literatura Comparada con la interculturalidad. In: CROLLA, A. (Org.). Lindes actuales de la Literatura Comparada. 1. Ed. Santa Fé: Universidad Nacional del Litoral, 2011. p. 126-136.

PALERMO, Z. Lugarizando saberes. Cadernos de estudos culturais, Campo Grande, MS, v. 2, p. 149-160, jul./dez. 2018.

QUIJANO, A. Colonialidad del poder, eurocentrismo y América Latina. In: QUIJANO, A. Cuestiones y horizontes: de la dependencia histórico-estructural a la colonialidad/descolonialidad del poder. Buenos Aires: CLACSO, 2014.

RAMA, A. Um processo autonômico: das literaturas nacionais à literatura latino-americana. Tradução de Nestor Deola. São Paulo, Argumento Revista Mensal de Cultura, n. 3, 1974, p. 3542.

RAMA, A. Transculturación narrativa en América Latina. 2. ed. Buenos Aires: Ediciones El Andariego, 2008.

SANTIAGO, S. O entre-lugar do discurso latino-americano. In: SANTIAGO, S. Uma literatura nos trópicos. 2. ed. Rio de Janeiro: Rocco, 2000, p. 09-26.

SANTOS, E. C. P. No princípio era a palavra, mas a palavra foi traduzida para os sinais. Cadernos de tradução, v. 38, n. 3, p. 93-124, set/dez, 2018. Disponível em: https://periodicos.ufsc.br/index.php/traducao/article/view/2175-7968.2018v38n3p93/37388.

Acesso em: 30 out. 2021.

SOMMER, D. Ficções de fundação: os romances nacionais da América Latina. Tradução de Gláucia Renate Gonçalves e Eliana Lourenço de Lima Reis. Belo Horizonte: Editora UFMG, 2004.

SOUSA SANTOS, B. Descolonizar el saber, reinventar el poder. Tradução de José Luis Exeni R.; José Guadalupe Gandarilla Salgado; Carlos Morales de Setién; Carlos Lema. Montevideo: Ediciones Trilce, 2010. 110 p.

TROUCHÉ, A. América: história e ficção. Niterói: EdUff, 2006.

USLAR PIETRI, A. Las carabelas del mundo muerto. In: USLAR PIETRI, A. Cuarenta ensayos. Caracas: Monte Avila Editores, 1990. p. 337-343.

WEINHARDT, M. Romance histórico: das origens escocesas ao Brasil finissecular. In: WEINHARDT, M. (Org.). Ficção histórica: teoria e crítica. Ponta Grossa: Editora UEPG, 2011, p. 12-55.

WYLER, L. Línguas, poetas e bacharéis: uma crônica da tradução no Brasil. Rio de Janeiro: Rocco, 2003.

Seguem sugestões de leitura, publicados pelo grupo de pesquisa, referentes, de alguma forma, aos estudos do romance Xicoténcatl (1826): 


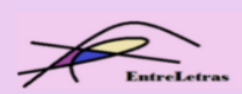

REVISTA ENTRELETRAS (ARAGUAÍNA), V. 12, N. 3, SET./DEZ. 2021 (ISSN 2179-3948 - ONLINE)

BERNDT, J.; DEL POZO GONZÁLEZ, L. S.; KLOCK, A. M. Um breve percurso pelo romance histórico por meio da leitura de Ivanhoé, Xicoténcatl, Mercedes of Castile e Crónica del Descubrimiento. Revell. 2021. No prelo.

BERNDT, J.; DEL POZO GONZÁLEZ, L. S. Xicoténcatl (1826), o primeiro romance histórico latino-americano. In: Congresso Internacional ABRALIC, 17., 2021, São Paulo.

CERDEIRA, P. de L.; DEL POZO GONZÁLEZ, L. S.; FLECK, G. F. A Primeira Tradução de Xicoténcatl ao Português Brasileiro (1826-2020): Traduzir para Resistir. Belas infiéis. 2021. p. 01-19. Link da publicação: https://periodicos.unb.br/index.php/belasinfieis/article/view/36130/31622

DEL POZO GONZÁLEZ, L. S. As primeiras representações literárias de Malinche em Xicoténcatl (1826): o impacto das imagens literárias na cultura mexicana. In: ANÔNIMO. Xicoténcatl: o primeiro romance histórico latino-americano. Tradução de Gilmei Francisco Fleck. Curitiba: CRV, 2020. pp. 47-71.

DEL POZO GONZÁLEZ, L. S. Malinche no espelho das traduções de Xicoténcatl (1826): [1999-2013]. 2017. 212f. Dissertação (Mestrado em Letras) - Universidade Estadual do Oeste do Paraná, Cascavel.

DEL POZO GONZÁLEZ, L.; ROHDE, M. L.; UBER, B. Construção da memória coletiva pela literatura: mulheres na América. LETRAS RARAS. 2020. p. 68-93. Link da publicação: http://revistas.ufcg.edu.br/ch/index.php/RLR/article/view/1756.

DEL POZO GONZÁLEZ, L.; BACA, F. La composición poética de los personajes indígenas femeninos en la literatura latinoamericana: Xicoténcatl (1826) e Iracema (1865). ENTRELETRAS. $\quad$ v. 11, n. 1, 2020. p. 291-310. Link da publicação: https://sistemas.uft.edu.br/periodicos/index.php/entreletras/article/view/9040/16740.

DEL POZO GONZALEZ, L. S. Apontamentos sobre Xicoténcatl (1826): reflexões para o ensino sobre o primeiro romance histórico latino-americano. In: FONSECA, A.; FLECK, G. F. SANTOS, L. S. (Org.). A pesquisa em literatura e leitura na formação docente: experiências da pesquisa acadêmica à prática profissional no ensino III. 1ed. Campinas: Mercado de letras, 2018, v. 3, p. 267-284.

DEL POZO GONZALEZ, L. S. Primeras novelas hispanoamericanas: entre la tradición y el enfrentamiento. In: DEL POZO GONZALEZ, L. S.; FLECK, G. F; DORADO MENDEZ, H. E. (Orgs.). El Universo literario en la enseñanza de español como lengua extranjera en Brasil. Porto Alegre: Unioeste/Evangraf, 2018, v. 1, p. 73-85.

DEL POZO GONZALEZ, L. S.; FLECK, G. F. La Malinche em Xicoténcatl (1826) e na história: o imaginário coletivo mexicano em configurações confrontadas. CRIOULA (USP), v. 1, p. $115,2017 . \quad$ Link da publicação: https://www.revistas.usp.br/crioula/article/view/125505/129998.

DEL POZO GONZÁLEZ, L.; FLECK, G. F. Brief Notes on the Portrayal of the Character Malinche in the English Translation of the First Latin American Historical Novel Xicoténcatl (1826). International journal of language and literature, v. 5, p. 9-19, 2017. p. 9-19. Link da publicação: http://ijll-net.com/journals/ij11/Vol_5_No_2_December_2017/2.pdf. 


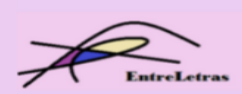

REVISTA ENTRELETRAS (ARAGUAÍNA), V. 12, N. 3, SET./DEZ. 2021 (ISSN 2179-3948 - ONLINE)

LOPES, R. S. Romances Históricos Americanos: The Last of The Mohicans (1826), Xicoténcatl (1826) e O Guarani (1857) Configurações das Identidades Ameríndias. 2015. 170 f. Dissertação (Mestrado em Linguagem e Sociedade) - Universidade Estadual do Oeste do Paraná, Cascavel, 2015. Link da publicação: http://tede.unioeste.br/handle/tede/2429.

Recebido em 07 de novembro de 2021 Aceito em 03 de janeiro de 2022 